\title{
CHAPTER
}

\section{INTRODUCTION TO AFRICAN AMERICAN PSYCHOLOGY AND POSITIVE PSYCHOLOGY}

The moment we choose to love we begin to move against domination, against oppression. . . towards freedom, to act in ways that liberate ourselves and others.

-Bell Hooks

\section{OBJECTIVES}

Readers will be able to:

- Define African American psychology and describe its development

- Define and highlight important constructs in positive psychology

- Describe the need for a positive psychology perspective of African American psychology

- Describe two models of development and how they influence our understanding of African Americans

- Discuss resiliency and models of resiliency in African Americans

\section{INTRODUCTION}

African Americans are a unique population due to their history of enslavement and oppression in the United States as well as their subsequent fight to build a place of equality for themselves. As it stands today, African Americans have made great strides toward this goal as they have gained political, economic, and social power. However, according to the National Urban League (2018), African Americans have achieved an Equality Index of $72.2 \%$ when compared to European Americans, suggesting that in the realms of economics, health, education, social justice, and civic engagement, there is more work to be done to gain parity. When we think about the psychological world of African Americans, there is no measure to tell us how psychologically healthy African Americans are. Such a complex measure would have to take into account so many factors including self-concept, motivations, well-being, sense of purpose, and mental health among others. This text starts on that journey by examining the strides that African Americans have made in the United States toward psychological health. We will explore their history, the current state of affairs, the mechanisms that play a role in psychological health, and how African Americans continue to prosper. 
Before moving too far into this text, it is important to provide some definitions for the groups of people that will be discussed in this text. When the term African American is used, it refers to people who have African ancestors who lived in the United States during the era of slavery. The term Black refers to anyone with African ancestry, including African Americans; this also includes Africans, Caribbean Blacks, and South American Blacks. Finally, when referring to people of color, that would include anyone of non-European descent. Understandably, this term in particular is somewhat problematic due to the large variety within the group, but due to the history or oppression by Europeans, the term people of color can be meaningful in some contexts.

\section{THE BIRTH OF AFRICAN AMERICAN PSYCHOLOGY}

Much of the early psychological research concerning African Americans has been from a deficit perspective, suggesting that African Americans are inferior to European Americans (e.g., Bowman, 2013; Caldwell-Colbert, Parks, \& Eshun, 2009; Hill, 1999; Lopez et al., 2002; Utsey, Giesbrecht, Hook, \& Stanard, 2008). Typically, this inferiority is believed to manifest from the environment, not biology, but there are exceptions to this line of thinking. For example, in the book, The Bell Curve (Herrnstein \& Murray, 1994), the authors postulated that African Americans had genetic deficits in intelligence. They suggested that African Americans had lower intelligence than European American for biological reasons, and therefore no interventions to support this population would have meaningful positive outcomes. If policy makers were to take such research as valid, many programs and agencies that support African Americans would likely not exist. Note that The Bell Curve is only a little over 25 years old, and there are still some who support its findings despite various examinations noting the flaws in their research (Haynes, 1995). Further reasons to doubt the authors' conclusions are our current knowledge of the importance of environment in determining intelligence as well as the cultural biases inherent in intelligence tests. Cultural biases reflect the fact that intelligence tests are often inaccurately derived and are developed from the perspective of the mainstream culture, ignoring the significant impact of other cultures on understandings of intelligence. Research from the deficit perspective, such as The Bell Curve, is not only an inaccurate method of understanding African Americans, it has greater ramifications by spreading negative beliefs about African Americans that often have real-world consequences.

\section{PROBLEMS WITH THE DEFICIT PERSPECTIVE}

It has been well established that much of the psychological literature is based upon a very unique sample, which has been labeled as WEIRD_Western, educated, industrialized, rich, Democraticby some researchers (Henrich, Heine, \& Norenzayan, 2010). According to Henrich and colleagues, the samples of American psychology undergraduates that fuel most of our psychological research knowledge are outliers, not just among international samples, but even in the United States. Their beliefs, views, and motivations are substantially different from most other human populations, primarily due to their extreme individualism. There has been a pattern of considering the values and beliefs of this group as the norm, and then interpreting that all of those who do not fit the norm are deficient (Jeglic, Miranda, \& Polanco-Roman, 2016). This is highly problematic when this WEIRD sample is actually very unique and not representative of human beings at large.

An example of how the practice of comparing African Americans to European American college samples is flawed is our understanding of medical mistrust. In European American samples, 
patients typically trust their doctors, feel good about their experiences with their doctors, and are therefore more likely to utilize the doctor's advice (Hudani, \& Rojas-Fernandez, 2016). African Americans are more likely to manifest less satisfaction with and mistrust of their doctors (Schoenthaler et al., 2014; Thames et al., 2012), however these views may be justified among African Americans due to a history of poor treatment by medical professionals and current discrepancies in the quality of treatment between African Americans and European Americans (Mattis et al., 2016). Medical mistrust may be an adaptive, protective choice for African Americans; therefore, merely comparing them to European Americans and saying that African Americans are deficient does not help the problem. A researcher who took the stance of deficiency would try to change the perceptions of African Americans, which would not help them if they are receiving substandard treatment. A researcher who recognizes the development and function of medical mistrust in African Americans would be more likely to work to change the system and better educate doctors so that African Americans are receiving appropriate care. This truly would address the problem. Using the deficit perspective to conduct research does not produce reliable, useful information. The comparisons merely tell us that there is a difference, but when the comparison sample is so unique, it is difficult to determine what that comparison really means. In order to better understand African Americans, researchers need to focus on examining processes of significance within African American samples, instead of comparing them.

Early psychological work, written from the deficit perspective, sparked African American psychologists to take the study of African Americans into their own hands. The Association of Black Psychologists (ABPsi) was born in 1968 out of African American psychologists' belief that the American Psychological Association (APA) was ignoring their concerns and interests. ABPsi members' main concerns were the problematic, often racist, research agenda concerning people of color as well as the low numbers of African American graduate students, APA committee members, and APA central office employees. This lack of representation indicated to African Americans that their needs were not being addressed and were not deemed important. ABPsi worked to represent African Americans by increasing the number of psychologists of color, and reshaping the way psychological research concerning people of color was conducted. Members of ABPsi pronounced that they were Black first, then psychologists. They prioritized the needs of the Black community.

In the early 1970s, the number of African Americans earning graduate degrees in psychology began to grow, providing the strength of numbers to be able to come together to begin addressing the problems with research focusing on African Americans. African American or Black psychology was born during this era. African American psychology focuses on understanding the emotional, psychological, and cognitive development of Black people in the United States.

As we begin to think about African American psychology, three key points are important to remember:

1. African Americans are diverse so we have to consider individuals. We must not assume that all African Americans are alike. In this book, it is impossible to address all possible manifestations of African American states of being.

2. Race is not biological, it is a social construction. Research has shown us that genes do not help us to differentiate between races, therefore, the term ethnicity will be used throughout this text to remind you that we are talking more about culture than any sort of biological difference. When race is used, the focus is on physical features that may identify a person as an African American such as skin color, hair texture, and facial features. 
3. The history of African Americans is crucial to understanding their psychology. Much discussion of history will take place to help us understand the best way for African Americans to move forward.

\section{IMPORTANT AFRICAN AMERICANS IN PSYCHOLOGY}

As we begin to explore African American psychology further, it is important to think about the psychologists and researchers that played significant roles in the early development of African American psychology.

Kenneth B. Clark (1914-2005) and Mamie Phipps Clark (1917-1983) conducted the original doll study that sparked concern about the self-esteem of African American children. Clark and Clark concluded from this study that Black children had low self-esteem and preferred European Americans over themselves. This study has been reproduced and replicated many times since its original form continuing to foster discussion and debate about African American children's self-perceptions. Conclusions from the doll study that the poor conditions of segregated schools fostered negative self-images in Blacks helped to support the Brown versus the Board of Education case that legislated the end of segregation in the educational setting. Clark and Clark were the first African Americans to receive doctoral degrees from Columbia University. During the late 1960s, Kenneth was the first African American president of the APA.

W. E. B. Du Bois's work, The Souls of Black Folk, though not necessarily psychology, was important to elucidating the challenges that African Americans faced throughout the United States during the early 20th century. He particularly addressed double consciousness-now thought of as biculturalism - that was necessary for African Americans to adapt. They had to be able to get along with other African American people, but also interact with European Americans. For some, it was a matter of life or death to be able to relate to European Americans in a manner that was perceived as non-threatening. Furthermore, his views about the importance of higher education to African Americans sparked debate about what was best for the African American community, a job-as suggested by individuals such as Booker T. Washington-or higher education, which according to Du Bois was critical in elevating a person's sense of self and crucial for the development of the African American community.

Robert Val Guthrie (1932-2005) was a founding member of the Association of Black Psychologists. He is best known for his book Even the Rat Was White: A Historical View of Psychology, which was one of the early texts that challenged the current state of psychology and elucidated the important contributions of African Americans to the field of psychology.

Inez Beverly Prosser (1897-1934) was the first black female psychologist, earning her PhD in psychology from the University of Cincinnati in 1933. Prosser's road toward her PhD was particularly challenging. After attending segregated schools through college in Texas, she had to leave Texas in order to obtain her graduate degrees. In her dissertation, she suggested that African American children in segregated schools with children and teachers of their own ethnicity were more secure, were more satisfied with their relationships with teachers, and less eager to leave school early than African American children in integrated schools. These conclusions were very controversial for the time. She died in a car accident only one year after obtaining her $\mathrm{PhD}$.

Francis Cecil Sumner (1895-1954) was the first African American to receive a PhD in psychology. His genius is noted in the fact that he did not attend high school, but was able to enter Lincoln University through an entrance exam and graduated magna cum laude. After obtaining 
his doctorate from Lincoln University, he studied racial bias. Unfortunately, his research was hampered by funding agencies denying him grants due to his ethnicity. He chaired the psychology department at Howard University, which he helped to found, from 1928 to 1954.

\section{CURRENT EVENTS}

\section{FEMALE AFRICAN AMERICAN APA PRESIDENTS}

Jessica Henderson Daniel became in 2018 the first African American woman to serve as the president of the American Psychological Association. She was also the first African American female elected to the APA Board of Directors. Daniel has worked since the early 1990s to improve training for psychologists, particularly in their practices with people of color. Furthermore, she has worked toward educating psychologists about resilience in African American children. Her career has focused on improving education, training, and mentoring to increase the quality and number of psychologists of color. The next president of APA was also an African American woman, Rosie Phillips Davis. Their elections as APA president demonstrate the strides that psychology and the APA have taken toward valuing and celebrating diversity.

\section{AFRICAN-CENTERED PSYCHOLOGY}

African-centered psychology considers the importance of African culture and the history of racism and oppression in the United States in understanding the psychology of African Americans. African-centered psychology states that African culture was not wiped from the minds of Blacks during slavery, but that it still plays a vital role in the lives of African Americans today. Psychologists such as Joseph White-who introduced us to the term Black psychology in 1970, Wade Nobles, and Na'im Akbar have played pivotal roles in the development and implementation of African-centered psychology. Concepts of importance to understanding African-centered psychology include maafa and sankofa. Maafa means disaster and refers to the devastation and horror of African enslavement and accompanying rejection of the humanity of Africans. Sankofa means that for one to go forward, one must look back. This emphasizes the value of knowing history to making progress. Both of these constructs will be important as we move through the text as the importance of the history of slavery on African Americans is discussed throughout the text. Furthermore, as noted above, this text is grounded in the history of African Americans and uses that knowledge to fuel understandings of the current state of African Americans. Furthermore, it is important to recognize the holistic nature of African perspectives, which includes the connection between individuals and everything around them as well as the importance of harmony and balance between self and the rest of the world (ma'at). In order to reach harmony and develop one's self, one must practice the seven cardinal virtues: truth, justice, balance, harmony, compassion, reciprocity, and order.

Other Afrocentric values that will be addressed in this text include spirituality and collectivism. Spirituality is an essential element of African cultures and refers to the relationships between individuals and higher powers. Across the world, those of African descent often continue to perceive spirituality as very important to their sense of self. Collectivism is the belief in a strong 
connection among a group of people that fosters interdependence and cooperative behavior in order to fulfill the needs of the group as a whole. This differs from an individualistic perspective in which a person is primarily motivated to prosper individually. A person with a collectivistic world view would work toward elevating significant others along with self, which may include family, friends, neighbors, and a wider community.

\section{AFRICAN AMERICAN PSYCHOLOGY TODAY}

Even today, where research has typically moved away from a deficit perspective, studies of African American often focus on risk-individual or environmental factors that interfere with the likelihood of positive outcomes for an individual-and negative outcomes (Mattis et al., 2016). It is important to understand the problems that African Americans face; however, we now have a wide knowledge base concerning the negative outcomes that some African Americans may endure. African Americans' history of slavery and oppression in the United States has placed them in a position in which they have had much to overcome. Over 150 years after the end of slavery and over 50 years after the passing of the Civil Rights Act, African Americans have higher unemployment rates, own fewer homes, have lower educational attainment, are more likely to live in poverty, and live shorter lives than European Americans (National Urban League, 2016). Furthermore, the stress of economic burdens negatively impacts African Americans psychologically and physically (Brody et al., 2013). At the same time, it is important to note that African Americans have come a long way in terms of equality, despite the societal and economic barriers that they face. It is time to shift from looking at the problems to focus on what is being done right. Yet, in 2013, only 5.4\% (4,559) of psychologists were African American (American Psychological Association [APA], 2015). A larger workforce is needed to be able to take on the task of pushing the research agenda concerning African Americans in a more positive direction. By examining strengths, we can cultivate them and use them to improve outcomes for a greater number of African Americans.

\section{THE DEVELOPMENT OF POSITIVE PSYCHOLOGY}

Positive psychology is a useful tool to move us away from the deficit perspective by focusing on the strengths of a population instead of the supposed weaknesses (Jeglic et al., 2016). Positive psychology is the study of factors related to living a happy, fulfilling life, including the factors that lead to it, the factors that are related to it, and the outcomes of living it. Seligman and Csikszentmihalyi (2000) state that the goal of positive psychology is to determine how to further develop strengths in individuals, not just cure weaknesses. Including human emotion such as well-being, positive personality traits such as self-regulation, optimism, and forgiveness, and the institutions that facilitate positive outcomes such as churches, schools, and community organizations, positive psychology helps to remind psychologists of the purpose for which psychology was developed. Psychologists often forget that originally, psychology was intended to help understand optimal human functioning, as well as to understand how people can live their best possible life. Psychology shifted to primarily focus on mental illness and deficits with the end of World War II and the development of government programs that funded the examination of these factors (Seligman \& Csikszentmihalyi, 2000). At that point, psychologists set aside one of their main goals-to find out how we could live happier, healthier lives by promoting our strengths. 
To foster continued research and understanding of positive psychology, Peterson and Seligman (2004) published Character Strengths and Virtues: A Handbook and Classification. This text identifies strengths and virtues that the authors believe are related universally to happy and fulfilled people who could overcome adversity. Though Character Strengths and Virtues does include international studies, it does not have the scope to fully examine how ethnicity and culture would influence our understanding of positive psychology constructs. Further, it was written from the perspective that positive psychology traits apply to all human beings and that they mean the same for everyone no matter the cultural and historical background.

\section{Culture and Positive Psychology}

The primary difficulty with positive psychology has been the assumption that these positive psychology traits are universal, which ignores the significant influence that culture and history has on individuals (e.g., APA, Task Force on Resilience and Strength in Black Children and Adolescents, 2008; Chang, Downey, Hirsch, \& Lin, 2016; Jeglic et al., 2016; Travis \& Leech, 2014). Positive psychology research has been conducted primarily from a Western and ethnocentric using one's own culture to judge and understand other cultures-perspective (Lopez et al., 2002), though Seligman and Czikszentmihalyi (2000) believe that their theory can move beyond culture and be applied to all human beings. Ignoring the impact of culture on positive psychology may lead to faulty knowledge about some populations. For example, there has been little research examining the impact of culture on our understanding of well-being (Jeglic et al., 2016), but it is possible that this factor is more important in European Americans than African Americans because of their greater sense of individualism. African Americans are typically more collectivistic than European Americans (Constantine \& Sue, 2006) and may give greater priority to the well-being of the group and less concern with their individual well-being, which is typically the focus of positive psychology research. This suggests that positive psychology needs to incorporate an understanding of the cultural, historical, political, and environmental context in which African Americans live (Mattis et al., 2016). Doing so will provide a better understanding of what can truly lead to a meaningful life for African Americans.

As we begin to explore the impact of culture on positive psychology and take more of a strength-based approach to understand how one lives a prosperous life, various elements of African American culture-ethnic-racial identity, biculturalism, collectivism, and religiosity/ spirituality, for example-must be more closely examined. We begin to understand also, that within the African American culture, there is much diversity. This book can neither address all of the areas of strength nor all of the diversity within African Americans, but it does consider these ideas.

\section{INTRODUCTION TO RESILIENCE}

One of the most important concepts to consider when thinking about positive psychology for African Americans is resilience. Once thought of as a static individual trait, today we realize that resilience is a dynamic process (Alvord, Rich, \& Berghorst, 2016; APA, Task Force on Resilience and Strength in Black Children and Adolescents, 2008; Masten, 2016). Resilience is a person's ability to overcome difficult situations or to thrive in the face of risk. Resilience is not just about the person's individual characteristics, but is also about their environment including their family, peers, community supports, and the larger society, as well as how those systems interact with each 
other. Resilience is complicated. For example, the resilience of children is so often based upon their family and caregivers, while the resilience of the family is dependent upon those systems which support the family such as neighbors and schools (Masten, 2016). To better understand resilience, we need to first explore models of development that give us a better idea of how systems work on individuals.

\section{Ecological Models of Development}

Systems are the complex interactions between the various parts of individual's lives which include the self, family, peers, the community, jobs, schools, the larger society, and more. Two important models can help us understand the contexts of African Americans' lives and how systems work, Bronfenbrenner's Ecological Model (1979) and Spencer's Phenomenological Variant of Ecological Systems (Spencer, 1995; Spencer, Dupree, \& Hartmann, 1997; Spencer et al., 2012) model.

Bronfenbrenner's Ecological Model (1979) separates the environment into the microsystem, mesosystem, exosystem, macrosystem, and chronosystem. The microsystem concerns factors that directly interact with the individual such as the immediate family, classmates, co-workers, and friends. The mesosystem is the connection between the settings that a person is involved in such as the family, school, church, and job. For example, academic support from a child's parents can lead to improved performance in school. The exosystem includes factors that influence an individual even though there may not be a direct relationship with them. This would include the passing of policies that results in a community center being opened which might result in less delinquency and crime in a neighborhood. The macrosystem includes the cultural beliefs and values that manifest in the microsystem and the mesosystem such as a family tradition of going to church as a family on New Year's Eve. The chronosystem considers the events that occur throughout an individual's life like transitioning from a student to an employee as well as including larger sociopolitical occurrences such as the Civil Rights Movement. Systems are complex because influence often does not only move in one direction; they are bi-directional. Individuals do not move through the world as isolated beings; people impact the environment and the environment impacts people. For example, a child who has an optimistic outlook on life may be treated well by his teacher because of their pleasant demeanor. This positive treatment from the teacher then reinforces that optimism and may lead to improved academic achievement. As parts of the system influence each other and the individual, the individual also impacts the system.

Phenomenological Variant of Ecological Systems Theory (PVEST; Spencer, 1995; Spencer et al., 1997; Spencer et al., 2012) is a model grounded in Bronfenbrenner's ecological theory that applies to African Americans specifically as it considers obstacles and protective factors that may impact identity formation. It is used to understand adaptive processes and identity development throughout the life span. According to PVEST, it is necessary to understand what events mean to the individual in addition to the factors that shape that meaning making, which is called phenomenology. This means it is important to consider people's evaluations of what an event signifies and how they believe that it will impact them. This may be why factors such as religion are particularly important to African Americans; religion often helps individuals to rationalize the events in their lives and accept them-particularly negative events. In addition, a person's ethnic-racial identity (beliefs about their ethnic group and sense of belong to the group) is significant because it plays a role in how we understand the events in our lives. PVEST examines five components: net vulnerability, net stress engagement, reactive coping processes, emergent identities, and stage-specific coping outcomes. These components are linked bi-directionally. Net vulnerability - an evaluation of whether a person has more risks or protective factors-determines whether 
a person is protected from or vulnerable to negative outcomes. The model also examines net stress engagement-experiences that can support (e.g., positive messages about one's ethnic group) or challenge (e.g., lack of support from parents) encounters with risk. Net stress engagement focuses on the person's daytoday experiences with risk factors and how those experiences impact them. Does the person become overwhelmed or persist when faced with a risk encounter? Reactive coping strategies address the fact that an individual can react negatively or positively. As one faces risks, a pattern of coping strategies or problem solving practices develops. For example, after a fight with a friend, a daughter may share her feelings with her mother (a positive coping strategy) or gossip about the friend with others (a negative coping strategy). The person's tendency to adopt certain coping strategies is considered emergent identities because a person's method of coping with the world becomes stable. The individual may begin to use certain coping practices first whenever faced with a stressor. In addition, there are self-appraisals related to this pattern of coping strategies so that a person may begin to think of himself as a worrier, doer, problem-solver, or otherwise. The self-appraisals lead to future self-beliefs and coping strategies resulting in coping outcomes that are either productive or unproductive. These productive or unproductive outcomes are their life-stage coping outcomes, which further influence their identity and can impact net vulnerability. The balance of these factors will shift across the lifespan. It is not a stagnant process. The presence of racism and discrimination in the American society presents as a significant risk for African Americans to cope with and therefore plays a major role in PVEST. According to PVEST, the context and how individuals make sense of it influence their stress level, how they cope with stress, and how they formulate their understanding of who they are.

\section{Models of Resilience}

There are various systems models of resilience targeting African Americans; among them are Bowman's model of resiliency (Bowman, 2013), a model or resilience or optimal functioning for African Americans as outlined by the APA (APA, Task Force on Resilience and Strength in Black Children and Adolescents, 2008), and Hill's resiliency framework (Hill, 2007). Resilience may be unique in African Americans as a result of their history in this country. Some posit that slavery and discrimination have facilitated the development of resilience in African Americans because they have had to strive to enjoy and find meaning in life despite the conditions in which they are immersed (Chao, 2010). The following models consider how resilience manifests in African Americans.

Bowman's Model of Resiliency (2013) examines chronic role strains, such as those due to being a student, employee, or family member, and how those roles are perceived. One's ability to cope with role strains is influenced by multilevel protective factors (support from society, institutions, community, family, or internal strengths), multilevel risk factors (societal barriers, poverty, or low socioeconomic status (SES), or psychosocial stressors), as well as life course and biological factors (age, genes, or family history). Risk factors, protective factors, and life course/biological factors interact to produce either adaptive or risky coping strategies that impact resilient outcomes. One important factor driving all of these constructs is social stratification-inequality that may be based on ethnicity, class, and/or gender. Bowman suggests that despite facing adversity, individuals can grow stronger by fighting against it; this is known as the adversity paradox. Individuals facing barriers may thrive particularly when they have strong multilevel protective factors (Bowman, 2013). In addition, exemplary intervention-programs and institutions designed to bolster strengths-may help to produce resilient outcomes. Bowman considers resilient outcomes to include positive emotional well-being, health status, and psychosocial development. 
The APA (2008) posits a model of African American resiliency based upon positive youth development research by Lerner, Dowling, and Anderson (2003). They suggest that there are four critical themes that should be examined when considering the resilience of African Americans: critical mindedness, active engagement, flexibility, and communalism. Critical mindedness guards one from the negative effects of discrimination and helps individuals to understand current social conditions. Active engagement would include proactive behaviors at home and in the community that may positively impact an individual's environment. This can include behaviors such as problem-solving and civic engagement. Flexibility suggests that people can adapt in various situations. Being bicultural-understanding and navigating the African American culture as well as mainstream culture-is an example of this. African Americans' flexibility within gender roles in the family system is another example. Finally, communalism considers the importance of connection with others and the collective nature of African Americans. Communalism can be seen across a number of arenas in African Americans' lives including within families and communities. The APA notes that there is much heterogeneity among African Americans, suggesting that this model takes that into account.

Hill's resilience framework (2007) includes an examination of protective mechanisms at the individual, family and community level that are based upon the strengths of African American families. Individual traits include academic ability, social skills, and internalizing positive values. Family traits include flexibility, positive communication and interaction, and positive family values. Community factors include utilizing the talents of those within the community and fostering the use of informal and formal community institutions. Hill $(1972 ; 1999)$ also identified five major strengths of African American families: strong work orientation, strong achievement orientation, strong religious orientation, strong kinship bonds, and flexible family roles, which arise in this resiliency framework as well. These strengths, according to Hill (1999), should be utilized to address the problems that are facing the African American community, including racism and economic instability. Research has demonstrated that African American therapists working with African American clients typically use these strengths noted by Hill in therapy to facilitate better therapeutic outcomes (Bell-Tolliver, Burgess, \& Brock, 2009), suggesting the merit of such a perspective.

\section{Resilience Research}

Recent research has helped us understand the process of resilience and the factors that play a role in it among many samples of African Americans including children (e.g., Brown, Barbarin, \& Scott, 2013), adolescents (e.g., Ernestus \& Prelow, 2015), college students (e.g., Utsey et al., 2008), Hurricane Katrina evacuees (e.g., Laditka, Murray, \& Laditka, 2010; Thomas, 2012), and the elderly (Baldwin, Jackson, Okoh, \& Cannon, 2011). Here, we merely introduce these ideas which will be examined more closely in the chapters to come.

In a study focusing on a nationally representative sample of African American boys, resilience against social skills deficits was examined (Brown et al., 2013). They followed these boys from kindergarten to fifth grade, finding that those who had higher general knowledge in kindergarten were less likely to manifest social skills problems five years later. This general knowledge was more important than the risk of maternal distress and low SES in predicting outcomes. The authors suggested that the boys' early knowledge fueled their resiliency and may have been an asset in developing socioemotional strengths while allowing them to internalize more adaptive coping mechanisms, and therefore manifest fewer social problems. 
Ernestus and Prelow (2015) followed African American and Hispanic youth from age 12 to five to six years later in three cities: Boston, Chicago, and San Antonio. Using the youth's individual and environmental characteristics, they separated them into three groups: resilient, at-risk, and mixed. They found that the resilient youth were less likely to be delinquent (in Chicago and San Antonio, not Boston), exhibited better psychological functioning, and had better quality romantic relationships, fewer sexual partners, and fewer pregnancies. When examining what made the resilient group more likely to have these better outcomes, they found that academic skills and positive neighborhood characteristics (low neighborhood problems, high connectedness and trust, and high community engagement) were those that bolstered the youth. Those most in danger of poor outcomes had low academic achievement, low school engagement, and low parental monitoring and trust. This suggests that it was a combination of individual, family, and community factors that played a role in risk and resilience among this sample.

Utsey et al. (2008) examined resilience in African American college students in a large, urban southwestern city. They found that greater resilience was related to more optimism and life satisfaction. Furthermore, having racial pride had a positive impact on optimism through its impact of resilience. They suggested that this racial pride may help African American college students adapt to stressors, particularly racism and discrimination. In addition, those who were more religious were also more optimistic. It is likely that their religious orientations provided them with greater hopes for their futures. This study highlights the importance of ethnic-racial identity and religion in understanding the psychological health of African Americans.

The slow response of the United States government in the face of the suffering that followed Hurricane Katrina was an eye-opening event for many Americans, but reinforced many of the ideas that African Americans already had about their place in American society. For psychologists, it provided an opportunity to gain a better understanding of how African Americans persist after traumatic events. Reviewing 17 studies conducted in the aftermath of Hurricane Katrina, Laditka and colleagues (2010) found that the primary coping mechanism employed by Hurricane Katrina evacuees was the use of religion and spirituality in the form of praying, reading the Bible, and seeking assistance from the church. A study focusing on older African American Katrina evacuees noted that many believed that they were protected by a higher power during the storm and their relocation afterwards (Thomas, 2012). Furthermore, they reported the importance of rebuilding a sense of community among other survivors after losing connections with family and friends, in addition to the importance of helping those around them. Religion and collectivism were important in helping African Americans to thrive after trauma.

An examination of resilience in an elderly African American sample noted that greater resilience was related to more optimism, fewer physical symptoms, and less anxiety (Baldwin et al., 2011). This study highlighted some of the heterogeneity within African Americans, stating that those who were lower- or working-class in the South, when compared to those living in the northern United States and those who were professionals, were the least optimistic and had the most psychological distress. Those in the South working in less prestigious jobs likely had more exposure to legal segregation and other racial stressors. Such findings elucidate the importance of context in understanding African Americans.

Taken together, these studies begin to highlight some of the strengths of African Americans that can be found across the lifespan and varying contexts. These studies elucidate the value of traits such as religiosity, strong ethnic-racial identity, and collectivism in facilitating positive outcomes for African Americans. As the traits that are related to resiliency begin to be uncovered, the next step is to determine how to develop these traits through intervention. 
TABLE 1.1 Factors Related to Fostering Resiliency

\begin{tabular}{|l|l|l|}
\hline INDIVIDUAL FACTORS & FAMILY FACTORS & COMMUNITY FACTORS \\
\hline Strong religious orientation & Connection/support & Peer support \\
\hline Self-efficacy & Strong kinship bonds & Neighborhood cohesion \\
\hline Ethnic-racial identity & Ethnic-racial socialization & Neighborhood safety \\
\hline Self-concept & Flexible family roles & School connection \\
\hline Strong work orientation & & Church membership \\
\hline Strong achievement orientation & & Social capital \\
\hline Creativity & & \\
\hline Biculturalism & & \\
\hline
\end{tabular}

\section{Fostering Resilience}

It is clear that building resilience is an important step toward improving the lives of African Americans in the United States. See Table 1.1 for factors related to fostering resilience. Several studies have undertaken the mission of empirically testing interventions designed to foster resilience (e.g., Belgrave, Chase-Vaughn, Gray, Addison, \& Cherry, 2000). Here, we will discuss three studies that have examined interventions for building resiliency and other strengths. The chapters that follow will provide more examples of these types of studies and examine their effectiveness.

\section{INTERVENTIONS IN PRACTICE}

\section{NAJA AND THE BRAVE PROGRAM}

Belgrave et al. (2000) examined outcomes of Naja (Safe) - a program designed to increase resilience in pre-adolescent girls living in a high poverty, high crime, high drug activity, and high teen pregnancy rate area of an East Coast city. They found that the intervention-which was designed to educate about feelings of self-worth, Afrocentric values, ethnic-racial identity, and gender identity once a week for four months-resulted in the girls having stronger Afrocentric values, ethnic-racial identity and physical appearance beliefs than a comparison group. The authors believed that the program acted as a buffer to girls who were transitioning into junior high school, a time when self-esteem often decreases. This study suggests that factors related to resilience can be increased with a relatively brief intervention, at least on a short-term basis.

The BRAVE (Building Resiliency and Vocational Excellence) Program was designed to reduce drug use in economically at-risk communities by developing resilient behaviors such as sense of purpose, social skills, and autonomy (Griffin, Holliday, Frazier, \& Braithwaite, 2009). These resiliency skills were fostered through a life skills curriculum and violence prevention program that included 


\section{INTERVENTIONS IN PRACTICE}

the development of career goals, occupational field trips and speakers, mentoring, and peer monitoring. Participants then practiced these skills in a variety of contexts-in school, the family, and the community. The eighth-grade African American students who participated in the intervention were less likely to drink alcohol and use marijuana at follow-up than the comparison group, suggesting that building resilience can have a positive impact of youth drug use.

An intervention examining resilience in African American adults with diabetes found positive results from their program (Steinhardt et al., 2015). The study included African Americans ranging from age 31 to 85 . The intervention focused on teaching participants coping strategies and building resilience so that they could psychologically and physically manage their diabetes. At a six-month follow up, program participants had better outcomes in knowledge (understanding of diabetes), mental health (ability to find a deeper, positive meaning in negative events), and physical aspects (healthier cholesterol and blood glucose levels). The authors believe that the participants felt more empowered by their knowledge and were able to utilize it to produce better psychological and health results.

\section{Limitations of Resilience}

As seen in the examples above, studies have begun to examine the positive outcomes of resilient individuals, yet resilience may be more complicated than it appears. Much of the research on resilience focuses on external measures of success such as academic success, ignoring internal measures such as biological health. Brody et al. (2013) have examined the physical toll that resilience may take on youth, particularly those in high risk environments. They studied African American youth in rural Georgia, following them from age 11 to 19 and examining resilience and potential outcomes. They found that youth with high socioeconomic risk who were high in resilience-as measured by self-control and competence-had higher allostatic load than those youth who were not in high SES risk environments or who were not high in resilience. Allostatic load is the biological toll on the body after exposure to chronic stress and can be measured by resting blood pressure, body mass index, and stress hormones. This finding suggests that when youth are at high risk and strive to overcome that risk, they pay for it with their health. This is connected to the construct of John Henryism in which persistent, effortful coping to overcome obstacles may result in significant health deficits. Brody and colleagues conclude that resilience may "only be skin deep" and suggest that we need to develop a better understanding of the biological cost of such efforts to achieve in the face of adversity.

Though we talk here about the importance of resilience within one's life, we have to remember those that do not come out of the other end unscathed. Some falter in the face of obstacles. We must remember that these individuals are not deficient. It is more likely that the systems that were supposed to support them-family, community, school-were unable to help them overcome the odds. We must not think of these individuals as failures because everyone can be resilient. We need to consider how to reshape the environment and try again. 


\section{CHAPTER SUMMARY}

This chapter began by introducing some of the challenges currently faced by African Americans in the United States. We then discussed the problems with the deficit perspective in understanding African Americans and the role of African American psychologists in the 1960s to attempt to move us away from this perspective. Key aspects of African-centered psychology were pointed out. The chapter went on to discuss individuals who were instrumental in the early days of Black psychology, helping us to understand their roles in addressing issues important to Blacks throughout the 20th century. The chapter then moved to discuss the rise of positive psychology and how it can uniquely help us to better understand African American psychology through its focus on strengths and not deficits. Resilience, a key concept in this book, was introduced along with ecological models of development and models of resiliency. Several empirical studies examining resilience were described along with interventions designed to increase resilience. Finally, we discussed the complexity of resilience and possible negative outcomes to resilience behavior.

\section{GLOSSARY}

Adversity paradox is the phenomenon in which an individual may have to face obstacles in order to develop resilience.

African American psychology is the study of psychology that focuses on understanding the emotional, psychological, and cognitive development of Black people in the United States.

African centered (Afrocentric or Black) psychology is the area of psychology that focuses on the way in which African philosophies affect the psychology of African Americans.

Allostatic load is the biological toll on the body after exposure to chronic stress as measured by indicators such as resting blood pressure, body mass index, and stress hormones.

Biculturalism is the psychological state when one person is able to successfully navigate two different cultures.

Bi-directional refers to the influence of constructs on each other such that they influence each other; the impact does not only move in one direction.

Bowman's Model of Resiliency examines chronic role strains and how one's ability to cope with role strains is influenced by multilevel protective factors, multilevel risk factors, as well as life course and biological factors.

BRAVE Building Resiliency and Vocational Excellence

Bronfenbrenner's Ecological Model is an ecological model that examines human development through the interactions between one's microsystem, mesosystem, exosystem, macrosystem, and chronosystem.

Chronosystem considers the significant personal and broader social events that occur throughout an individual's life.

Collectivism is the belief in a strong connection among a group of people that fosters interdependence and cooperative behavior in order to fulfill the needs of the group.

Cultural biases are the inaccurate tendency to understand and develop ideas from the perspective on one's own culture, ignoring the significant impact of other cultures.

Deficit perspective is an early approach to examining ethnic minorities in research in which people of color were compared with European Americans and viewed as inferior when differences were found. 
Ethnocentric refers to using one's own culture as the basis to judge and understand other cultures.

Exosystem includes parts of the environment that influence an individual even though there may not be a direct relationship with them.

Hill's Resilience Framework is a model that focuses on the strengths of African American families while including related individual, family, and community factors.

Individualism is a worldview in which a person is primarily concerned with his or her own needs and less concerned with the needs of the collective.

John Henryism is the state in which persistent, effortful coping to overcome obstacles may result in significant health deficits for individuals who chronically experience other stressors.

Maafa means disaster and refers to the devastation and horror of African enslavement and accompanying rejection of the humanity of Africans.

Ma'at is the moral code of conduct in Afrocentric perspectives that includes the seven cardinal virtues of truth, justice, balance, harmony, compassion, reciprocity, and order.

Macrosystem includes the cultural beliefs and values that manifest in the microsystem and the mesosystem

Mesosystem is the connections between the different aspects of a person's environment such as family, school, and work.

Microsystem concerns factors that directly interact with the individual such as the immediate family, classmates, co-workers, and friends.

Phenomenological Variant of Ecological Systems Theory is a model grounded in Bronfenbrenner's ecological theory that applies to African Americans specifically as it considers identity formation.

Phenomenology refers to an understanding of what events mean to the individual in addition to the factors that shape that meaning making.

Positive psychology is the study of factors related to living a happy, fulfilling life including the factors that lead to it, the factors that are related to it, and the outcomes of living it.

PVEST Phenomenological Variant of Ecological Systems Theory.

Resilience is a person's ability, which is influenced by internal and external factors, to overcome difficult situations or to thrive in the face of risk.

Risk refers to individual or environmental factors that interfere with the likelihood of positive outcomes for an individual.

Sankofa in the Akan language means that for one to go forward, one must look back. This emphasizes the value of knowing history to making progress.

SES Socioeconomic status

Social stratification is the hierarchical categorizing of people based upon social status, wealth, or power.

Socioeconomic status is a measure of social standing that considers factors such as wealth, income, education level, and occupation.

Systems are the complex interactions between the various parts of individual's lives, which include the self, family, peers, the community, jobs, schools, the larger society, and more.

WEIRD is the acronym for Western, educated, industrialized, rich, Democratic which is used to describe most participants of psychological research. 


\section{DISCUSSION QUESTIONS}

1. Why is it so problematic to compare African American samples to WEIRD samples?

2. Why was there a need for African American psychology in the late 1960s and early 1970 s? Why is there still a need for this branch of psychology?

3. How does positive psychology offer a solution to problems of the deficit perspective in understanding African American psychology?

4. Why is it important to consider the environment when we think about the development or individuals? What are some environmental factors that might be important?

\section{ADDITIONAL RESOURCES}

\section{Articles}

Butler, B. S. T., Leath, S., Williams, A., Byrd, C., Carter, R., \& Chavous, T. M. (2018). Promoting resilience among African American girls: Racial identity as a protective factor. Child Development, 89(6), e552e571. doi:10.1111/cdev.12995

Follins, L. D., Walker, J. J., \& Lewis, M. K. (2014). Resilience in Black lesbian, gay, bisexual, and transgender individuals: A critical review of the literature. Journal of Gay \& Lesbian Mental Health, 18(2), 190-212. doi:10.1080/19359705.2013.828343

\section{Books}

Chang, E. C., Downey, C. A., Hirsch, J. K., \& Lin, N. J. E (Eds.). (2016). Positive psychology in racial and ethnic groups: Theory, research, and practice. Washington, DC: American Psychological Association.

Guthrie, R. V. (1998). Even the rat was white: A historical view of psychology. Boston, MA: Allyn and Bacon. Peterson, C., \& Seligman, M. P. (2004). Character strengths and virtues: A handbook and classification. Washington, DC: American Psychological Association.

\section{Documentaries}

Lending, T. (Director). (2016). All the difference. Nomadic Pictures.

This video follows two African American youth as they thrive despite being from a high risk environment.

\section{Websites}

American Psychological Association. Retrieved from https://www.apa.org Association of Black Psychologists. Retrieved from http://www.abpsi.org

\section{REFERENCES}

Alvord, M. K., Rich, B. A., \& Berghorst, L. H. (2016). Resilience interventions. In J. C. Norcross, G. R. VandenBos, \& D. K. Freedheim (Eds.), APA handbook of clinical psychology: Psychopathology and health (pp. 505-519). Washington, DC: American Psychological Association. doi:10.1037/14862-023

American Psychological Association. (2015). Demographics of the U.S. psychology workforce: Findings from the American Community Survey. Washington, DC: Author. 
American Psychological Association, Task Force on Resilience and Strength in Black Children and Adolescents. (2008). Resilience in African American children and adolescents: A vision for optimal development. Washington, DC: Author. Retrieved from https://www.apa.org/pi/families/resources/ resiliencerpt.pdf

Baldwin, D. R., Jackson, D. I., Okoh, I., \& Cannon, R. L. (2011). Resiliency and optimism: An African American senior citizen's perspective. Journal of Black Psychology, 37(1), 24-41. doi:10.1177/0095798410364394

Belgrave, F. Z., Chase-Vaughn, G., Gray, F., Addison, J. D., \& Cherry, V. R. (2000). The effectiveness of a culture- and gender-specific intervention for increasing resiliency among African American preadolescent females. Journal of Black Psychology, 26(2), 133-147. doi:10.1177/0095798400026002001

Bell-Tolliver, L., Burgess, R., \& Brock, L. J. (2009). African American therapists working with African American families: An exploration of the strengths perspective in treatment. Journal of Marital and Family Therapy, 35(3), 293-307. doi:10.1111/j.1752-0606.2009.00117.x

Bowman, P. J. (2013). A strengths-based social psychological approach to resiliency: Cultural diversity, ecological, and life span issues. In S. Prince-Embury \& D. H. Saklofske (Eds.), Resilience in children, adolescents, and adults: Translating research into practice (pp. 299-324). New York, NY: Springer Science + Business Media. doi:10.1007/978-1-4614-4939-3_21

Brody, G. H., Yu, T., Chen, E., Miller, G. E., Kogan, S. M., \& Beach, S. H. (2013). Is resilience only skin deep?: Rural African Americans' socioeconomic status-related risk and competence in preadolescence and psychological adjustment and allostatic load at age 19. Psychological Science, 24(7), 1285-1293. doi:10.1177/0956797612471954

Bronfenbrenner, U. (1979). The ecology of human development: Experiments by nature and design. Cambridge, MA: Harvard University Press.

Brown, J., Barbarin, O., \& Scott, K. (2013). Socioemotional trajectories in Black boys between kindergarten and the fifth grade: The role of cognitive skills and family in promoting resiliency. American Journal of Orthopsychiatry, 83(2-3), 176-184. doi:10.1111/ajop.12027

Caldwell-Colbert, A. T., Parks, F. M., \& Eshun, S. (2009). Positive psychology: African American strengths, resilience and protective factors. In H. A. Neville, B. M. Tynes, \& S. O. Utsey (Eds.), Handbook of African American Psychology (pp. 375-384). Thousand Oaks, CA: Sage Publications, Inc.

Chang, E. C., Downey, C. A., Hirsch, J. K., \& Lin, N. J. (2016). Positive psychology in racial and ethnic groups: A second call to action! In E. C. Chang, C. A. Downey, J. K. Hirsch, \& N. J. Lin (Eds.), Positive psychology in racial and ethnic groups: Theory, research, and practice (pp. 3-12). Washington, DC: American Psychological Association. doi:10.1037/14799-001

Chao, R. C. (2010). Well-being and resilience. In R. L. Hampton, T. P. Gullotta, \& R. L. Crowel (Eds.), Handbook of African American health (pp. 106-120). New York, NY: Guilford Press.

Constantine, M. G., \& Sue, D. W. (2006). Factors contributing to optimal human functioning in people of color in the United States. The Counseling Psychologist, 34(2), 228-244. doi:10.1177/ 0011000005281318

Ernestus, S. M., \& Prelow, H. M. (2015). Patterns of risk and resilience in African American and Latino youth. Journal of Community Psychology, 43(8), 954-972. doi:10.1002/jcop.21725

Griffin, J. J., Holliday, R. C., Frazier, E., \& Braithwaite, R. L. (2009). The BRAVE (Building resiliency and vocational excellence) program: Evaluation findings for a career-oriented substance abuse and violence preventive intervention. Journal of Health Care for the Poor and Underserved, 20(3), 798-816. doi:10.1353/ hpu. 0.0174

Haynes, N. M. (1995). How skewed is "The Bell Curve"? Retrieved from http://files.eric.ed.gov/fulltext/ ED379382.pdf

Henrich, J., Heine, S. J., \& Norenzayan, A. (2010). The weirdest people in the world? Behavioral and Brain Sciences, 33(2-3), 61-83. doi:10.1017/S0140525X0999152X

Herrnstein, R. J., \& Murray, C. A. (1994). The bell curve: Intelligence and class structure in American life. New York, NY: Free Press

Hill, R. B. (1972), The strengths of Black families. New York, NY: Emerson Hall Publishers.

Hill, R. B. (1999), The strengths of African American families: Twenty-five years later. New York, NY: University Press of America.

Hill, R. B. (2007). Enhancing the resilience of African American families. In L. A. See (Ed.), Human behavior in the social environment from an African American perspective (pp. 49-61). Binghamton, NY: The Haworth Press. 
Hudani, Z. K., \& Rojas-Fernandez, C. H. (2016). A scoping review on medication adherence in older patients with cognitive impairment or dementia. Research in Social \& Administrative Pharmacy, 12(6), 815-829. doi:10.1016/j.sapharm.2015.11.011

Jeglic, E. L., Miranda, R., \& Polanco-Roman, L. (2016). Positive psychology in the context of race and ethnicity. In E. C. Chang, C. A. Downey, J. K. Hirsch, \& N. J. Lin (Eds.), Positive psychology in racial and ethnic groups: Theory, research, and practice (pp. 13-33). Washington, DC: American Psychological Association. doi:10.1037/14799-002

Laditka, S. B., Murray, L. M., \& Laditka, J. N. (2010). In the eye of the storm: Resilience and vulnerability among African American women in the wake of Hurricane Katrina. Health Care for Women International, 31(11), 1013-1027. doi:10.1080/07399332.2010.508294

Lerner, R. M., Dowling, E. M., \& Anderson, P. M. (2003). Positive youth development: Thriving as the basis of personhood and civil society. Applied Developmental Science, 7(3), 172-180. doi:10.1207/ S1532480XADS0703_8

Lopez, S. J., Prosser, E. C., Edwards, L. M., Magyar-Moe, J. L., Neufeld, J. E., \& Rasmussen, H. N. (2002). Putting positive psychology in a multicultural context. In C. R. Snyder \& S. J. Lopez (Eds.), Handbook of positive psychology (pp. 700-714). New York, NY: Oxford University Press.

Masten, A. S. (2016). Resilience in developing systems: The promise of integrated approaches. European Journal of Developmental Psychology, 13(3), 297-312. doi:10.1080/17405629.2016.1147344

Mattis, J. S., Simpson, N. G., Powell, W., Anderson, R. E., Kimbro, L. R., \& Mattis, J. H. (2016). Positive psychology in African Americans. In E. C. Chang, C. A. Downey, J. K. Hirsch, \& N. J. Lin (Eds.), Positive psychology in racial and ethnic groups: Theory, research, and practice (pp. 83-107). Washington, DC: American Psychological Association. doi:10.1037/14799-005

National Urban League (2016). 2016 State of Black American Executive Summary and Key Findings: Locked Out: Education, Jobs \& Justice. New York: Author.

National Urban League. (2018). 2018 State of Black America. Retrieved from http://soba.iamempowered. com/2018-report

Peterson, C., \& Seligman, M. P. (2004). Character strengths and virtues: A handbook and classification. Washington, DC: American Psychological Association.

Schoenthaler, A., Montague, E., Manwell, L. B., Brown, R., Schwartz, M. D., \& Linzer, M. (2014). Patientphysician racial/ethnic concordance and blood pressure control: The role of trust and medication adherence. Ethnicity \& Health, 19(5), 565-578. doi:10.1080/13557858.2013.857764

Seligman, M. P., \& Csikszentmihalyi, M. (2000). Positive psychology: An introduction. American Psychologist, 55(1), 5-14. doi:10.1037/0003-066X.55.1.5

Spencer, M. B. (1995). Old issues and new theorizing about African American youth: A phenomenological variant of ecological systems theory. In R. L. Taylor (Ed.), Black youth: Perspectives on their status in the United States (pp. 37-69). Westport, CT: Praeger.

Spencer, M. B., Dupree, D., \& Hartmann, T. (1997). A phenomenological variant of ecological systems theory (PVEST): A self-organization perspective in context. Development and Psychopathology, 9(4), 817-833. doi:10.1017/S0954579497001454

Spencer, M. B., Dupree, D., Tinsley, B., McGee, E. O., Hall, J., Fegley, S. G., \& Elmore, T. G. (2012). Resistance and resiliency in a color-conscious society: Implications for learning and teaching. In K. R. Harris, S. Graham, T. Urdan, C. B. McCormick, G. M. Sinatra, J. Sweller, ... J. Sweller (Eds.), APA educational psychology handbook, Vol 1: Theories, constructs, and critical issues (pp. 461-494). Washington, DC: American Psychological Association. doi:10.1037/13273-016

Steinhardt, M. A., Brown, S. A., Dubois, S. K., Harrison, L. J., Lehrer, H. M., \& Jaggars, S. S. (2015). A resilience intervention in African-American adults with type 2 diabetes. American Journal of Health Behavior, 39(4), 507-518. doi:10.5993/AJHB.39.4.7

Thames, A. D., Moizel, J., Panos, S. E., Patel, S. M., Byrd, D. A., Myers, H. F., . . Hinkin, C. H. (2012). Differential predictors of medication adherence in HIV: Findings from a sample of African American and Caucasian HIV-positive drug-using adults. AIDS Patient Care and STDS, 26(10), 621-630. doi:10.1089/ apc.2012.0157

Thomas, C. L. (2012). Exploring resiliency factors of older African American Katrina survivors. Journal of Evidence-Based Social Work, 9(4), 351-368. doi:10.1080/15433714.2010.525411 
Travis, R. J., \& Leech, T. J. (2014). Empowerment-based positive youth development: A new understanding of healthy development for African American youth. Journal of Research on Adolescence, 24(1), 93-116. doi:10.1111/jora.12062

Utsey, S. O., Giesbrecht, N., Hook, J., \& Stanard, P. M. (2008). Cultural, sociofamilial, and psychological resources that inhibit psychological distress in African Americans exposed to stressful life events and race-related stress. Journal of Counseling Psychology, 55(1), 49-62. doi:10.1037/0022-0167.55.1.49 